\title{
Formulation of Comprehensive Business Model for Future Logistics Foray as a Third Party Logistic Player for Warehouse Services
}

\author{
Shiv Prakash Teli \\ Lecturer Govt. Polytechnic college chittorgarh (Rajasthan) \\ Dr. Dinesh Shringi
}

Associate professor MBM Engg. College Jodhpur Faculty of Engineering, JNVU Jodhpur (Rajasthan)

\author{
H.K. Sharma \\ Scientific Officer-G Heavy Water Rawatbhata Via Kota (Rajasthan)
}

\begin{abstract}
A Third-party logistics provider (abbreviated 3PL) is a firm that provides outsourced or "third party" logistics services to companies for part, or sometimes all of their supply chain management functions. Third party logistics providers typically specialize in integrated warehousing and transportation services that can be scaled and customized to customer's needs based on market conditions and the demands and delivery service requirements for their products and materials. The third party logistics (3PL) market in India is still in a relatively nascent stage. While multinational companies in all industries have been predominant users of these services, domestic majors in leading industrial sectors have also begun to follow the footsteps of their multinational counterparts, starting with outsourcing their basic logistics functions. Realizing the significant cost reductions and several other benefits gained by these companies, a large number of small to medium companies in all the industries are gearing up to use 3PL services for their logistic functions, resulting in tremendous potential for 3PL market in India. In India total warehousing size is 1200 Billion, which is growing $40 \%$ Y - OY growth. Only $8 \%$ of private warehousing segment is organized. So there is huge opportunity in this space. As a Part of the Rs. 6500 Crore Future Group (Pantaloons Retail), Future Logistics caters to End to end logistics requirements for the retail operations of group companies like Pantaloons, Food Bazaar, and Central across 85 retail formats. Incorporated in 2007, FLSL has 800 employees, a pan-India warehousing presence of 3.5 Million Sq. feet and a dedicated transport fleet of 200 trucks. So considering with future demand and future logistics capability, it can serve as 3PL service provider across industry.

Main objectives of this study are mentioned here under:

1. Try to measure the scope of 3PL in improving operational efficiency and financial performance of any organization.

2. Formulation of comprehensive business model for future logistics foray as a third party logistics player for warehouse services.

3. Analysis of current 3PL market in India.

4. Identification of future logistic strength.

5. Understanding of current market driver and future roadmap of 3PL service provider.
\end{abstract}

Keywords:3PL (Third party logistics), YOY (Year over Year), FLSL (Future Logistics Service Limited), ERP(Enterprise Resource Planning), SKU( Stock Keeping Unit ), WMS( Warehouse Management System), VAT( Value added Tax), GST ( Goods and Services Tax), GDP( Gross Domestic Product).

\section{INTRODUCTION}

A third-party logistics provider (abbreviated 3PL) is a firm that provides outsourced or "third party" logistics services to companies for part, or sometimes all of their supply chain management functions. Third party logistics providers typically specialize in integrated warehousing and transportation services that can be scaled and customized to customer's needs based on market conditions and the demands and delivery service requirements for their products and materials. 


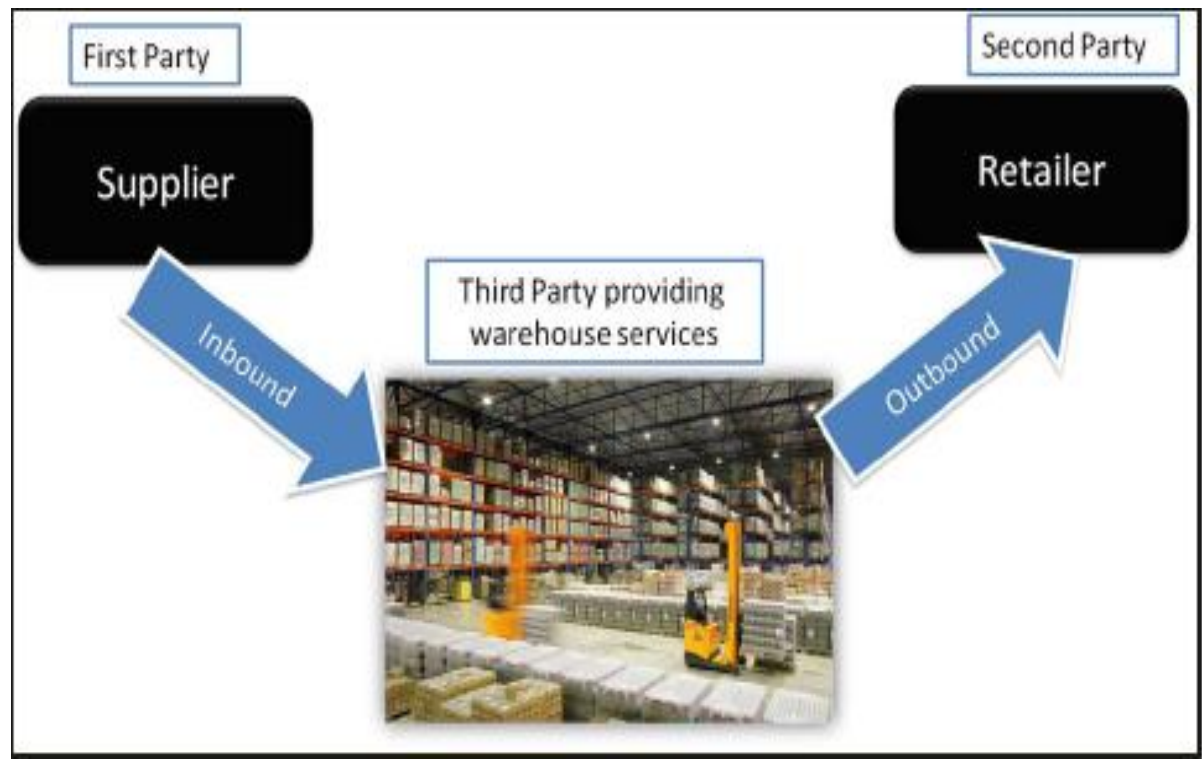

II. CLASSIFICATION OF 3PL PROVIDERS

We can classify 3PL providers as given below

2.1 Standard 3PL provider: This is the most basic form of a 3PL provider. They would perform activities such as, pick and pack, warehousing, and distribution (business) - the most basic functions of logistics. For a majority of these firms, the 3PL function is not their main activity.

2.2 Service developer: This type of 3PL provider will offer their customers advanced value-added services such as: tracking and tracing, cross-docking, specific packaging, or providing a unique security system. A solid IT foundation and a focus on economies of scale and scope will enable this type of 3PL provider to perform these types of tasks

2.3 The customer adapter: this type of 3PL provider comes in at the request of the customer and essentially takes over complete control of the company's logistics activities. The 3PL provider improves the logistics dramatically, but do not develop a new service. The customer base for this type of 3PL provider is typically quite small.

2.4 The customer developer: this is the highest level that a 3PL provider can attain with respect to its processes and activities. This occurs when the 3PL provider integrates itself with the customer and takes over their entire logistics function. These providers will have few customers, but will perform extensive and detailed tasks for them. The third party logistics (3PL) market in India is still in a relatively nascent stage. While multinational companies in all industries have been predominant users of these services, domestic majors in leading industrial sectors have also begun to follow the footsteps of their multinational counterparts, starting with outsourcing their basic logistics functions. Realizing the significant cost reductions and several other benefits gained by these companies, a large number of small to medium companies in all the industries are gearing up to use 3PL services for their logistic functions, resulting in tremendous potential for 3PL market in India.

\section{TARGET AREA FOR FUTURE LOGISTIC IN 3PL}

The practices in Indian industry reveal that: Warehousing, inbound and outbound transportation, custom clearing and forwarding are the most frequently outsourced activities. Activities like packaging; fleet management and consolidation are gaining attention and growing in popularity. More and more companies are planning to use 3PL services in the future as an integrated set of services rather than for just movement of material.

The motivation for doing so comes due to the benefits of logistics cost reduction, ability to focus on the core business, and improving supply chain efficiency. Though the usage of 3PL services reveals positive and significant impact on business performance, third party logistics practices are still at a nascent stage in India. $55 \%$ of companies subscribe to $3 \mathrm{PL}$ services as compared to $75 \%$ globally and these seem to be more of transportation and warehousing related activities. 
Organizations will increase the usage of 3PL services in traditional logistics activities and increase the scope of outsourcing based on the overall satisfaction and the impact on business objectives logistics system performance, customer satisfaction and employee morale. These indicators should help the 3PL service providers plan the depth and scope of their service offerings in India. They clearly highlight the importance of delivering results that impact the business objectives in order to increase outsourcing opportunities for Indian organizations.

III.

FUTURE LOGISTICS WAREHOUSING CAPABILITIES

\section{Pan India presence}

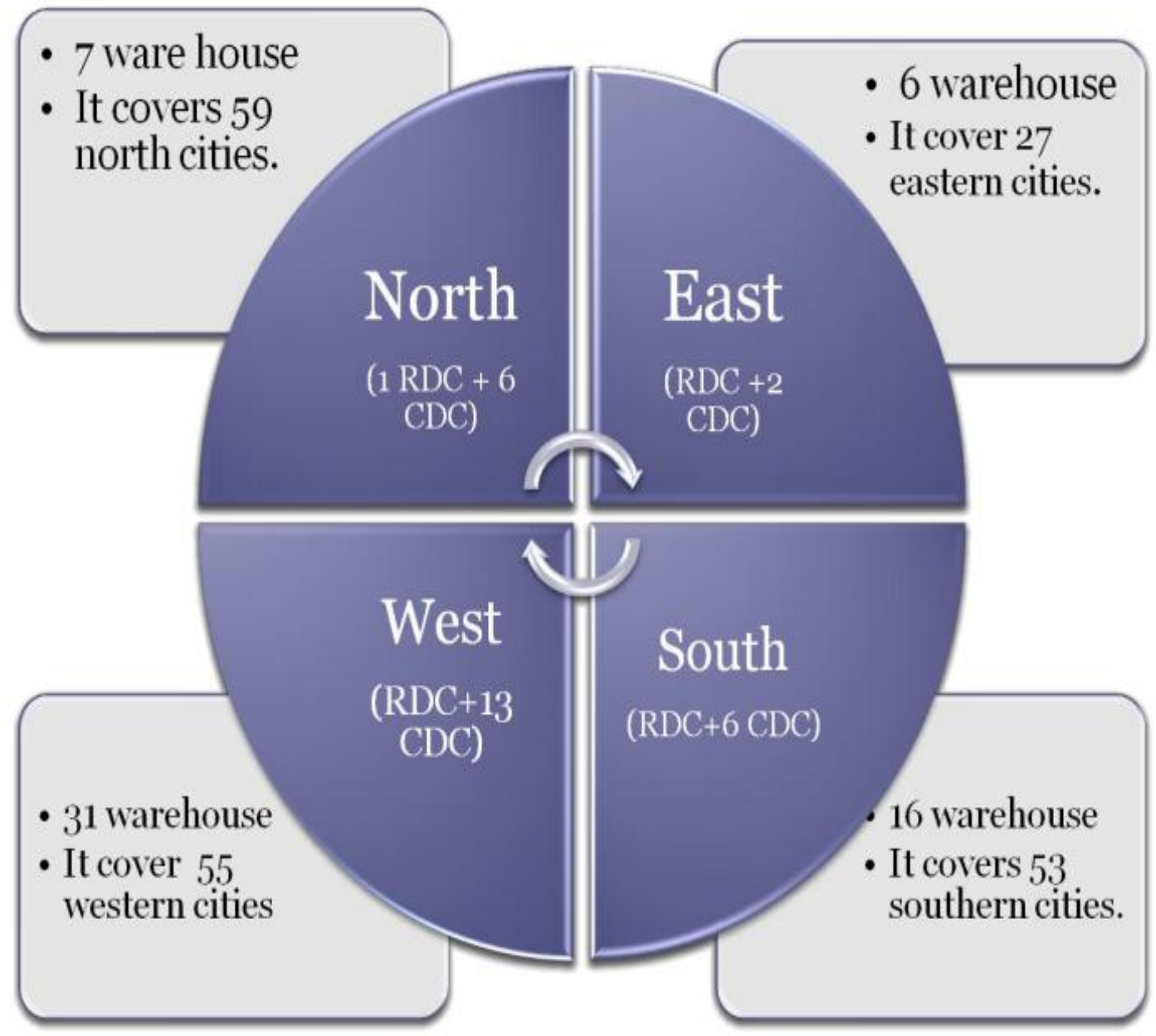

- The Storage \& Fulfilments vertical of Future Supply Chains provides storage \& handling solutions through a current warehouse footprint of over 3.5 million sqft across 67 locations - the largest by any Supply Chain player in India. This vertical includes supply chain network modelling, processes, layout \& systems designing, capital procurement, installation \& operation for MHE \& technology (Racking, Reach Trucks, Sorters, Conveyors, RF Scanners, other automation etc.); and productivity \& cost optimization. The key differentiators in warehousing are :

- Low cost operations based on the company's ability to lease large spaces and offer mechanization

- Enhanced service efficiency based on WMS enabled multi level storage and seamless integration with customer ERP.

- Service efficiency arising out of the company's ability to handle multiple SKUs.

- Eaches picking i.e. picking of individual pieces as against case-wise picking.

- Ability to handle widely differentiated product groups; and their seasonality, cyclicality, and demand patterns.

- Ability tominimise obsolescence 24x7 Operations Managing sales and business commercials of customers.Testing, Packaging, refurbishing, bar coding and other value added services 
Future Supply Chains' core competency is creating an efficient replenishment system - the most critical function for any supply chain backend. This finely honed capability of the company, is being offered to its customers, so that they can gain from its experience and expertise.

Future Supply Chains' capability enables it to handle an average of 1.5 million pieces everyday with peak single-day transactions reaching 4 million pieces.

\section{SWOT ANALYSIS FOR FUTURE LOGISTIC OPPORTUNITIES \& GROWTH} DRIVERS

GST/VAT regime: Consolidation through

large scale centralized warehousing

\section{Rapid Growth in organized retail}

\section{Increasing trend towards outsourcing}

\section{Free Trade Warehousing Zones}

\section{GROWTH IN ORGANIZED RETAIL SECTOR}

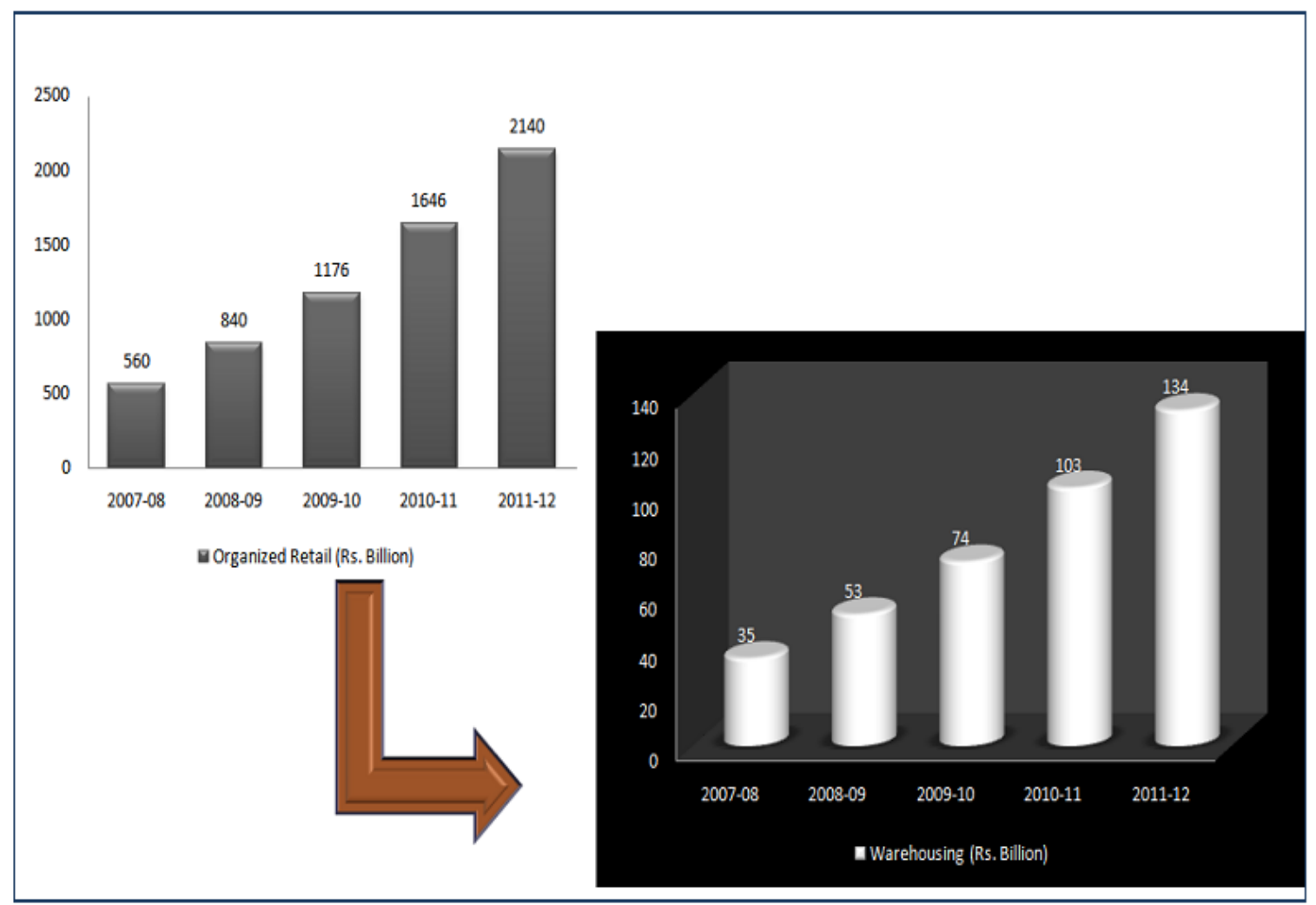

Figure: Growth in organized retail driving market size for warehousing 


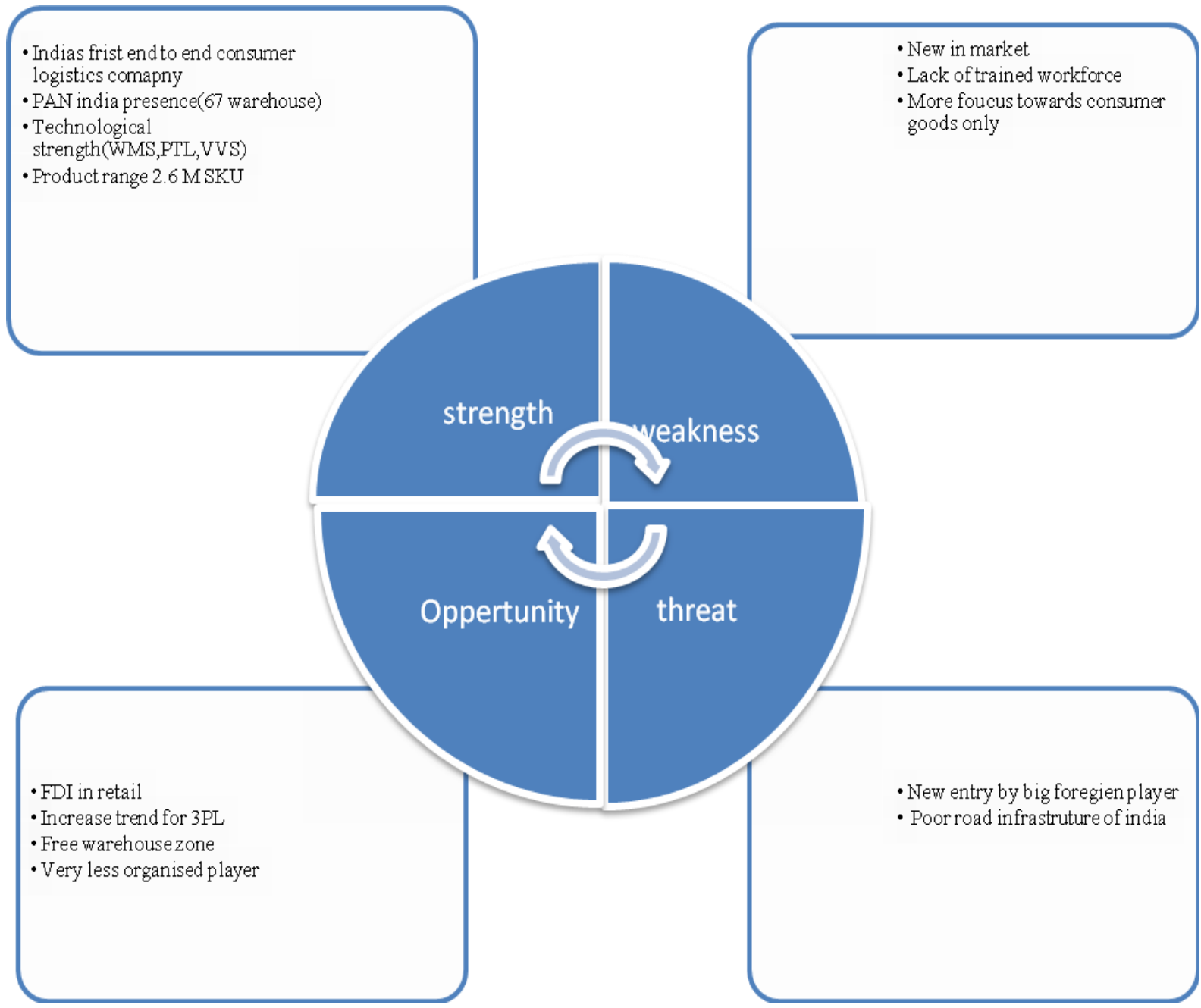

\section{FUTURE SCOPE;}

1. Designing warehouse network as per distribution plans of organized retail players.

2. Target market segmentation for organized player.

\section{LIMITATION;}

Since the private warehousing sector is highly unorganized, the challenges that Future Logistics would face are more external in nature than internal. This means that the challenges that it will face will be common across industry. These are as following

\section{Poor Infrastructure}

India's spend on logistics activities - equivalent to 13 percent of its GDP is higher than that of the developed nations. The key reason for this is the relatively higher level of inefficiencies in the system, with lower average trucking speeds, higher turnaround time at ports and high cost of administrative delays being just a few of the examples.

\begin{tabular}{|c|c|c|}
\hline Country & Logistics Cost/GDP & $\begin{array}{c}\text { Share of 3PL in } \\
\text { overall Logistics }\end{array}$ \\
\hline India/China & $13-15 \%$ & $<10 \%$ \\
\hline US & $9.9 \%$ & $57 \%$ \\
\hline Europe & $10 \%$ & $30-40 \%$ \\
\hline Japan & $11.4 \%$ & $80 \%$ \\
\hline
\end{tabular}

Source: SSKI Report 
These inefficiencies have arisen over the years from a combination of a non-conducive policy environment, extensive industry fragmentation and lack of good basic infrastructure. India's indirect tax regime discouraged large centralized warehouses and led, over time, to fragmentation in the warehousing sector. Extensive fragmentation meant the incapacity of industry players to develop the industry as a whole and poor support infrastructure, such as roads, ports and telecom, led to a situation where the opportunity to create value is limited.

\section{Lack of trained manpower}

The core issues leading to the existing skill gaps in the sector are

- Poor image / lack of attractiveness for new recruits arising from poor working conditions and relatively lesser attractive pay and progression incentives - in turn arising from the fragmented and unorganized nature of the industry.

- Rapid evolution in the logistics management processes and operations with technological change and changing customer requirements.

- Absence of an institutionalized skill development environment

- Emergence of attractive alternate career options leading to attrition (especially in sectors where logistics skills come in handy like organized retail)

\section{Delay in Implementation of tax reforms}

The government has been dilly dallying over the implementation of VAT. Even then this is not implemented uniformly over all states. Such disparity will not lead to uniform expansion of centralized warehousing structure. With elections scheduled around 2014, implementation of the radical GST/VAT system might face lot of roadblocks.

1. Poor Infrastructure.

2. Lack of trained warehousing manpower.

3. Delay in Implementation of tax reforms.

4. Companies loss its control on particular function which is outsourced with the help 3PL.

\section{CONCLUSION}

Commitment towards logistics infrastructure and regulations around rationalization of tax structures are creating an environment of positive change for warehousing and logistics sector in general. 3PL Players now have the opportunity to leverage economies of scale, complemented with better infrastructure, to provide integrated logistics solutions which are cost effective.

Rapid growth of organized retail and the need to reach out to the large untapped rural markets in India are necessitating development of strong back end and front end supply networks. The organized retail boom will drive the warehousing market as has been demonstrated in the retail booms in US. The market for warehousing for organized retail will grow from existing 35 Billion Rs to 154 Billion Rs by 2014.

Tapping into the trends of increasing logistics outsourcing to 3PL companies, Future Logistics can effectively serve the needs of organized retail. With a pan India warehousing network it has the foundation to meet the location wise proximity needs of retail stores. Also with a expertise and facilities of serving reputed customer in categories of apparel, general merchandise, food \& beverages and consumer durables, with significant market share.

With a robust technology backbone and an accomplished manpower, Future Logistics Solutions Ltd is projected to have revenues of Rs. 32 Crores in 2009 and go on to Rs. 90 Crores in 2014.

\section{REFERENCES}

[1]. Mulcahy David, "Warehouse Distributions and Operations Handbook", McGraw-Hill.

[2]. Mitra Subrata, , "A Survey of the Third-Party Logistics (3PL) Service Providers in India", IIM Calcutta working paper series 2005.

[3]. "Foreign Trade Policy 2004-2009: Preparing India for the world", Cargo Times, Vol 4, No 7, September 2004, pp 5-6.

[4]. KPMG 'Skill Gaps in the Indian Logistics Sector', 2006.

[5]. Bhatnagar, R., Sohal, A.S. and Millen, R., "Third party logistics services: a Singapore perspective", International Journal of Physical Distribution and Logistics Management, 1999, Vol. 29 No. 9, pp. 569587.

[6]. Bloomen, D.R.V. and Petrov, I.P., "Logistics in Bulgaria: Concepts for New market Expansion", International Journal of Physical Distribution and Logistics Management, 1998, Vol. 24 No. 2, pp. 30-36.

[7]. www.futuregroup.in 